\title{
Electrocardiogram Standard Unit
}

National Cancer Institute

\section{Source}

National Cancer Institute. Electrocardiogram Standard Unit. NCI Thesaurus. Code C83270.

The standard unit of measure for electrocardiogram results. 